\title{
Challenges to food grain production in the current climate change scenario for ensuring food security in India: A strategic review
}

\author{
Dujeshwer Kurrey ${ }^{1}$, Md. Afjal Ahmad ${ }^{2}$, Saxena R.P.N. ${ }^{3}$ and Ram Kumar Singh ${ }^{1,4}$ \\ ${ }^{1,4}$ Department of Agronomy \\ ${ }^{2}$ Department of Plant Physiology \\ ${ }^{3}$ Department of Entomology and Agril. Zoology,Institute of Agricultural Sciences, Banaras Hindu University, \\ Varanasi-221005, India
}

\begin{abstract}
Food security is a major growing challenge in most of the developing countries including India where the problem is more pronounced given the vagaries of climate change, overgrowing population, shrinking land area and unsustainable agricultural practices. In the past decades, climate has drastically changed in the form of severe drought, erratic rainfall, high temperature etc. which has disturbed the phenology, physiology and productivity of most of the agricultural crops. The concept of food security can be better discussed under its three key components viz. food availability, food accessibility and food utilization. Among these three, food availability has a direct bearing on how we orient our agricultural production system in the contemporary threat of global warming. Moreover there has been irregular occurance and performance of weather parameters which in turn has compelled the scientific community to address these issues so that agriculture can become climate resilient and be responsive to the abrupt changes that occurs in the biotic as well as abiotic sphere of the ecosystem. Thus, here an attempt has been made to review the challenges which comes in the way of securing food security in the country especially in the context of growing concerns of climate change and few future perspectives and conclusive works that has been done so far in tackling the problem of global warming coupled with sustaining the agricultural production system.
\end{abstract}

KEY WORDS: FOOD SECURITY, DROUGHT, CLIMATE RESILIENT AGRICULTURE

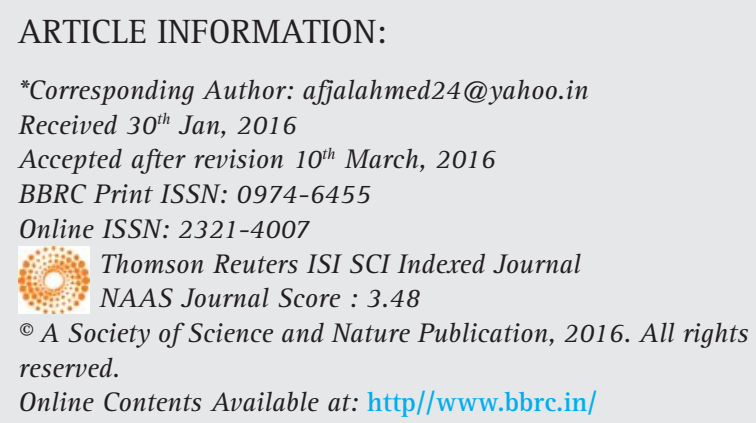




\section{INTRODUCTION}

Climate change has now been considered as an inevitable danger to the whole agriculture production system, the effects of which are highly unpredictable and needs a comprehensive appraisal as to what are the causes and implications of these dangers on our crop plants with special emphasis on cereal plants (Bill and Gates, 2014). Recent studies suggest the world will need to produce 60 to $100 \%$ more food when the global population will reach 9 billion people by 2050 (FAO, 2013). The most widely cited study is FAO which projects a 70 percent increase in food production between 2005/2007 to 2050. (Van Dijk and Meijerink (2014). As the result of intensive research and breeding efforts over the last 20 years, the yield potential and yield quality of cereals have been greatly improved. Nowadays, yield safety has gained more importance because of the forecasted climatic changes.

Drought and high temperature are especially considered as key stress factors with high potential impact on crop yield. Yield safety can only be improved if future breeding attempts will be based on the valuable new knowledge acquired on the processes determining plant development and its responses to stress. Plant stress responses are very complex. Interactions between plant structure, function and the environment need to be investigated at various phases of plant development at the organismal, cellular as well as molecular levels in order to obtain a full picture. The results achieved so far in this field indicate that various plant organs, in a definite hierarchy and in interaction with each other, are involved in determining crop yield under stress. Here it is attempted to summarize the currently available information on cereal reproduction under drought and heat stress and to give an outlook towards potential strategies to improve yield safety in cereals (ADB, 2013).

Abiotic stresses such as extreme temperatures and low water availability frequently limit the growth and productivity of major crop species including cereals. High temperature is often accompanied with low water supply, so the primary aim of cereal breeding must be to develop cultivars tolerating both types of stresses (Tester and Bacic, 2005). The success of cereal reproduction as well as the realization of the yield potential of a given cultivar, however, are dependent not only on the stress sensitivity of the reproductive and grain-filling stages but on overall plant growth and development. Efficient photosynthesis and stem reserve accumulation during the vegetative phase has a decisive role on the formation of generative organs and thus may directly affect final yield (Blum et al., 1994). Therefore, in order to improve yield safety in cereals, the whole developmental proc- ess, from grain to grain, needs to be considered and appropriate strategies may target several developmental stages (Triboi and Triboi-Blondel, 2002).

\section{EFFECT OF ELEVATED TEMPERATURE/ HEAT STRESS ON PLANTS}

Changes in the global climate, notably in regional spatial and temporal temperature patterns, are predicted to have important consequences for crop production .Both plant growth and development are affected by temperature. The most significant factors for heat stress-related yield loss in cereals include the high-temperature-induced shortening of developmental phases, reduced light perception over the shortened life cycle and perturbation of the processes associated with carbon assimilation (transpiration, photosynthesis and respiration) (Stone, 2001). Increased respiration requires greater carbon fixation for sustained growth and survival. Temperatures higher than $35^{\circ} \mathrm{C}$ significantly decrease the activity of ribulose 1.5-bisphosphate carboxylase/oxygenase (Rubisco), thereby limiting photosynthesis.

Heat stress during vegetative growth causes many physiological and metabolic changes, including alterations in hormone homeostasis. Some of the heat-induced processes at the cell, organ and whole-plant levels may be hormone regulated; others may be the consequence of a new hormonal status, altered by heat stress (Maestri et al., 2002). In field conditions where water shortage and high-temperature stresses frequently occur simultaneously, ABA induction may also be an important component of thermo tolerance. The effect of gibberellins on high-temperature tolerance is the reverse of that of $A B A$ (Maestri et al., 2002).

One of the consequences of heat stress in plants is oxidative damage caused by the heat-induced imbalance of photosynthesis and respiration. Elevated temperatures may reduce the activities of antioxidant enzymes, as observed in maize. Accordingly, in a set of wheat (Triticum aestivum) genotypes, the capacity to acquire thermo tolerance was correlated with higher activities of catalase and superoxide dismutase, higher ascorbic acid content and less oxidative damage (Sairam et al., 2000; Almeselmani et al., 2006). High growing temperature reduces the duration of all developmental stages in wheat thereby squeezing its phenolgy, in such conditions, plant growth promoting rhizobacteria ( PGPR) plays a greater role in ameliorating the heat stress (Meena et al., 2015)

\section{HIGH TEMPERATURE AND FLOWER INITIATION}

Losses in cereal yields can be attributed to heat stressinduced metabolic changes, to a decrease in the duration of the developmental phases of plants and the conse- 
quent reduction in light perception over the shortened life cycle, and to the perturbation of processes related to carbon assimilation (transpiration, photosynthesis and respiration), all of which may lead to fewer and/or malformed and/or smaller organs (Maestri et al., 2002). Wheat plants have four to eight leaves on the main shoot when the growing apex changes from the vegetative to the reproductive stage. Temperatures above $30^{\circ} \mathrm{C}$ during floret formation cause complete sterility reported a positive correlation between the length of the vegetative phase and the number of spikelets per spike. Therefore, shortening the duration of the vegetative stage of the apex induces fewer spikelets per spike. The main effect of heat stress after/during floral initiation is observed on kernel number. The number of kernels per unit area decreases at a rate of 4\% for each degree increase in mean temperature during the $30 \mathrm{~d}$ preceding anthesis. Considerable experimental effort has been devoted to examining carbohydrate availability for developing wheat florets as a major factor in the grain number (Demotes et al., 2004).

\section{EFFECT OF HEAT STRESS ON FLOWERING AND FERTILIZATION}

High-temperature stress $\left(>30^{\circ} \mathrm{C}\right)$ from early meiosis to pollen maturity also has a damaging effect on the viability of pollen grains in wheat, resulting in a failure of fertilization, and thus in a reduction in seed set. Increased temperature over the mid-anthesis period decreased the grain number per ear at maturity in spring wheat (Ferris et al., 1998) indicating the heat sensitivity of fertilization and grain setting. The heat sensitivity of the pollen might be explained by its inability to synthesize all the HSPs. High-temperature stress at flowering reduces spikelet fertility in rice (Oryza sativa L.). Sterility is caused by poor anther dehiscence (caused by the tight closure of the locules) and low pollen production, and hence low number of germinating pollen grains on the stigma (Matsui and Omasa, 2002; Prasad et al., 2006). In maize, reduction in seed set occurs at temperatures higher than $38^{\circ} \mathrm{C}$ mainly because of a reduction in pollen germination ability and pollen tube elongation (Stone, 2001). Lateral ear heating (by $4.5^{\circ} \mathrm{C}$ above the air temperature in the heated zone) prior to silk emergence reduced the kernel number per ear (Cárcova and Otegui, 2001).

\section{GRAIN FILLING UNDER HEAT AND DROUGHT}

Grain filling is the final stage of growth in cereals, where fertilized ovaries develop into caryopses. Its duration and rate determine the final grain weight, a key component of the total yield. High temperature and drought are the major stress factors during the maturation and ripening of cereals in many production areas. Periods of water limitation as well as of high temperature during grain development cause large yield losses in cereals. This reduction is mainly caused by a reduction in starch accumulation, because, in general, over $65 \%$ of cereal dry weight (DW) is accounted for by starch. The reduction in grain weight in response to drought or heat stress during the early periods of grain filling can mainly be attributed to the lower number of endosperm cells, while during the later stages stress results in the impairment of starch synthesis either because of the limited supply of assimilates for the grain or the direct effects on the synthetic processes in the grain (Yang et al., 2004).

\section{THE EFFECT OF WATER LIMITATION AND HIGH TEMPERATURE ON GRAIN DEVELOPMENT}

The maximum amounts of starch and protein that accumulate in each grain depend on the number of endosperm cells, determined early in grain fill, and the final size of the cells, which is influenced by the rate and duration of grain fill. In maize, the application of a high-temperature treatment $\left(35^{\circ} \mathrm{C}\right.$ for 4 or $\left.6 \mathrm{~d}\right)$ during the mitotic phase of the endosperm cell cycle $(4,6$ and $8 \mathrm{~d}$ after pollination) was found to be more deleterious, inhibiting the entry of the mitotic cells into the endo reduplication cycle (Engelen et al., 2001). Chronic high temperature up to a mean of $27{ }^{\circ} \mathrm{C}$ (daytime maximum of $30^{\circ} \mathrm{C}$ ) during kernel filling has a similar effect to drought, with a significant reduction in the duration in grain fill and only a marginal increase in its rate (Wardlaw, 2002). High temperature $\left(37 / 17^{\circ} \mathrm{C}\right)$ from anthesis to maturity caused a significant reduction in the starch accumulation period in developing wheat grains compared with plants grown under control $\left(24 / 17^{\circ} \mathrm{C}\right)$ conditions (Hurkman et al., 2003)

\section{MECHANISMS OF CELLULAR ADAPTATION TO WATER DEFICIT AND ELEVATED TEMPERATURE}

The first step in switching on a specific response to an environmental signal, such as drought, is the perception of the signal by specific receptor(s). Plant responses to drought may rely on several mechanisms that sense water status, turgor, bound water, hormones (e.g. ABA), alteration in cell membranes, etc. (Chaves et al., 2003). A transmembrane histidine kinase receptor (ATHK1) and associated proteins forming a potential 'osmosensor' have already been implicated in the perception of water deficit in Arabidopsis. It is very likely, however, that there are further, yet unknown, mechanisms by which plant cells sense water deficiency (Chaves et al., 2003). 


\section{MODERN APPROACHES TO THE IMPROVEMENT OF YIELD IN CEREALS UNDER TEMPERATURE AND MATER STRESS}

Environmental stresses have a great impact on the yield of cereal crops. As detailed earlier, the effect of drought and/or heat stress on yield is highly complex and involves processes as diverse as stem reserve accumulation, gametogenesis, fertilization, embryogenesis, and endosperm and grain development. Our present knowledge on these processes and on their mutual interactions is still scant, especially if the potential impacts of environmental factors also have to be considered. The application of modern research tools to reveal the complex molecular networks behind the observed physiological and developmental responses in higher plants, including cereals, has only recently begun.

Good genetic maps based on molecular marker technologies are now available for major cereal species (Snape et al., 2005; Langridge et al., 2006). Many of the traits determining a biotic stress tolerance and the quality and quantity of yield are controlled by a large number of genes, which have only minor individual effects but which act together (quantitative trait loci, QTL). In crop species with large, complex genomes, QTL analysis is an important tool in the identification of genetic markers to assist breeding efforts. This approach is complicated in wheat because of the polyploid nature of the genome and the low levels of polymorphism, but is straightforward in rice, maize and barley (Snape et al., 2005).

Expression profiling may help identify the key molecular events underlying stress tolerance and grain development, as well as their interactions. The number of cereal expressed sequence tag (EST) sequences available in public databases is continuously increasing. The cDNA libraries used to generate these ESTs represent various tissues and growth conditions, but yield- and stress-related libraries dominate. ESTs are especially important in wheat genomics, where wholegenome sequencing is unlikely to be completed in the near future because of the size and complexity of the genome. Recently (Houde et al., 2006) reported that the digital expression analysis of EST sequences combined with gene annotation (annotation of 29,556 different sequences) resulted in the identification of several pathways associated with abiotic stress resistance in wheat.Genetic modification allows the introduction of isolated individual genes into the cereal germplasm and offers a variety of opportunities to increase environmental stress tolerance. The major cereal species are all amenable to the technologies of genetic modification (Vasil, 2007).

\section{FUTURE PERSPECTIVES AND SUGGESTIONS}

The complexity of both cereal reproduction and plant stress responses makes it difficult to construct a simple model of ways in which successful reproductive development and high yield can be achieved under water-limited and/or high-temperature conditions. Both specific and more general approaches are conceivable, targeting various aspects of plant development and stress responses. However, where the safety of the final yield is concerned, all the breeding or genetic manipulation approaches used in cereals have to converge finally at flowering and/or grain development. Therefore, the better understanding of these developmental processes is of utmost importance for the future, and modern genomic approaches may help considerably in this respect. However, cereal yield is not only dependent on the success of the reproductive processes themselves, but is indirectly determined by overall plant growth and development as well. This is well supported by the breeding of modern cultivars with reduced plant height (most of the cereal species) or tassel size (maize), with concomitant improvement in assimilate availability for the growing spike, thus enhancing kernel number.

Environmental stresses have a great impact on the reproductive development of cereal crops and, consequently, on the final yield. The effect of drought and/or heat stress on yield is highly complex and involves processes as diverse as nutrient assimilation and supply to reproductive organs, stem reserve accumulation, gametogenesis, fertilization, embryogenesis, and endosperm and grain development. Despite the fact that yield can be affected at any time from sowing to grain maturity, it is generally accepted that only certain periods of the whole growing season are critical for the determination of the final yield in cereals

\section{CONCLUSION}

Growing concerns over climate change and possible threat that it poses on the agricultural production systems has compelled scientists and policy makers to shift their research targets to one that is inter disciplinary and more resilient and policies that are more consistent and responsive to changes implicated in realizing the goal of food and nutritional security in developing countries specially in India. Therefore it is the need of the hour to integrate and conceptualise the existing production systems and to link it with programs that strives to develop crops more resilient to climate change. Hence, modern genetic and genomic tools linked to physiological and field experiments will provide more and more experi- 
mental details about the link between the various climate change indicators and varied agro ecosystem that it affects with special reference to response of cereal crops to high temperature regime.

\section{REFERENCES}

ADB (2013). Food security in Asia and the Pacific. Mandaluyong City, Philippines: Asian Development Bank. 3-65.

Almeselmani M., Deshmukh P.S., Sairam R.K., Kushwaha S.R. and Singh T.P. (2006). Protective role of antioxidant enzymes under high temperature stress. Plant Science 171; 382-388.

Bill and Mellinda Gates (2014). Sustainable Agriculture, Food Security and Nutrition in the Post-2015 Framework, Bill and Mellinda Gates Foundation. Discussion paper. 4-8.

Blum A., Sinmena B., Mayer J., Golan G. and Shpiler L. (1994). Stem reserve mobilisation supports wheat grain filling under heat stress. Australian Journal of Plant Physiology 21, 771-781.

Cárcova J. and Otegui M.E. (2001). Ear temperature and pollination timing effects on maize kernel set. Crop Science $41,1809-1815$.

Chaves M.M., Maroco J.P. and Pereira J.S. (2003). Understanding plant responses to drought: from genes to the whole plant. Functional Plant Biology 30, 239-264.

Demotes-Mainard S. and Jeuffroy M.H. (2004) Effects of nitrogen and radiation on dry matter and nitrogen accumulation in the spike of winter wheat. Field Crops Research 87, 221-233.

Engelen-Eigles G., Jones R.J. and Phillips R.L. (2001). DNA endoreduplication in maize endosperm cells is reduced by high temperature during the mitotic phase. Crop Science 41; 11141121.

FA0, IFAD and WFP. (2013). The State of Food Insecurity in the World;The multiple dimensions of food security. Rome, FAO.

Ferris R., Ellis R.H., Wheeler T.R. and Hadley P. (1998). Effect of high temperature stress at anthesis on grain yield and biomass of field-grown crops of wheat. Annals of Botany 82, 631-639.

Houde M., Belcaid M. and Ouellet F. (2006). Wheat EST resources for functional genomics of abiotic stress. BMC Genomics 7; 149.

Hurkman W.J., McCue K.F. and Altenbach S.B. (2003). Effect of temperature on expression of genes encoding enzymes for starch biosynthesis in developing wheat endosperm. Plant Science $164 ; 873-881$.

Langridge P., Paltridge N. and Fincher G. (2006). Functional genomics of abiotic stress tolerance in cereals. Briefings of Functional Genomics and Proteomics 4, 343-354.
Maestri E., Klueva N., Perrotta C., Gulli M., Nguyen T. and Marmiroli, N. (2002). Molecular genetics of heat tolerance and heat shock proteins in cereals. Journal of Plant Molecular Biology 48; 667-681.

Matsui T. and Omasa K. (2002). Rice (Oryza sativa L.) cultivars tolerant to high temperature at flowering: anther characteristics. Annals of Botany 89; 683-687.

Meena H., Ahmad M.A. and Prakash P. (2015). Amelioration of heat stress in wheat by PGPR (Pseudomonas aeruginosa strain 2CpS1). Biosci. Biotech. Res. Comm. 8(2): 171-174.

Prasad P.V.V., Boote K.J., Allen L.H., Jr., Sheehy J.E. and Thomas J.M.G. (2006). Species, ecotype and cultivar differences in spikelet fertility and harvest index of rice in response to high temperature stress. Field Crops Research 95; 398411 .

Sairam R.K., Srivastava G.C. and Saxena D.C. (2000). Increased antioxidant activity under elevated temperatures: a mechanism of heat stress tolerance in wheat genotypes. Biologia Plantarum 43; 245-251.

Snape J., Fish L., Leader D., Bradburne R. and Turner A. (2005). The impact of genomics and genetics on wheat quality improvement.Turkish Journal of Agriculture and Forestry 29; 97-103.

Stone P. (2001). The effects of heat stress on cereal yield and quality. In Crop Responses and Adaptations to Temperature Stress (ed.A.S.Basra), pp. 243-291. Food Products Press, Binghamton, NY, USA.

Tester M. and Bacic M. (2005). Abiotic stress tolerance in grasses. From model plants to crop plants Plant Physiology 137; 791-793.

Triboï E. and Triboï-Blondel A.M. (2002). Productivity and grain or seed composition: a new approach to an old problem. European Journal of Agronomy 16; 163-186.

Van Dijk M. and Meijerink G. (2014). A review of global food security scenario and assessment studies: results, gaps and research priorities. Food secure Working paper-20.

Vasil I.K. (2007). Molecular genetic improvement of cereals: transgenic wheat (Triticum aestivum L.). Plant Cell Reports 26;1133-1154.

Wardlaw I.F. (2002). Interaction between drought and chronic high temperature during kernel filling in wheat in a controlled environment. Annals of Botany 90; 469-476.

Yang J.C., Zhang J.H., Wang Z.Q., Xu G.W. and Zhu Q.S. (2004). Activities of key enzymes in sucrose-to-starch conversion in wheat grains subjected to water deficit during grain filling. Plant Physiology 135;1621-1629. 